\title{
A Tissue Engineering Discussion for Mechanical / Chemical Engineers - Introducing the Operation of the Stem-Cells Activation Triggers
}

\author{
Edilson Gomes de Lima \\ IENN-Institute Engineering in Nanoscience and Nanotechnology, Australia
}

Copyright $(2018$ by authors, all rights reserved. Authors agree that this article remains permanently open access under the terms of the Creative Commons Attribution License 4.0 International License

\begin{abstract}
This paper traced an introductory script about the natural communication by an interface between the tissues and the environment theoretically, as a possible form of biological adaptation in environment, as a first step for popularization in tissue engineering for mechanical and chemical engineers. Knowing the keys communication system, it's theoretically possible to understand that even after generating a specialized tissue, it is still possible to induce new stem cells to generate tissues. According to external and internal tissues readings, as by integrin mechanism, or actomyosin induced by various means, presented throughout this study. Also, make visible and clear new stem cells induction techniques through stimuli, activated by means for the formation of specialized and interconnected specialized cells for tissue engineering. In this objective investigation is showed some mechanical analytical apparatus in new designs to automate biological processes. The domain of all flow and mechanism in stem cell activation triggers is as important as the knowledge of DNA sequencing, with the focus on proving the ability of the tissues to read passively, interpret the external environment and make changes by biochemicals for appropriate adaptation. The genes interpret the environmental stimuli, human senses interfaces and activate adult stem cell niches. External factors along the stem cell are the focus of this investigation, e.g. it has already been proven that a specific nanotopography is a platform to induce differentiation control in stem cells. By nanotopography a stem cell can being induced to become a specific tissue. Through the control and listing these activation keys through mechanical engineering and logic, we can create true artificial tissue factories in high precision innovative scaffolds geometries, with final objective new addictive manufacture and innovative architecture for biological circuits.
\end{abstract}

Keywords Biomanufacturing, iPSCs, Mechanical
Engineering, Nanotopography, Scaffolds, Tissue
Engineering

\section{Introduction}

The world changes surge new sciences and technologies emerge. By human interferences in the environment the flora and fauna are suffering changes, in behaviour and biological. The environment interface with biology in adaptation process is in a disastrous running. For a better and one possible environmental remediation, there are hundreds of emerging technologies. Critical subjects such as cyborgs, atomic printers, biomechanics and mimicry natural biologic circuits are decisive at present. Are themes that involve mechanical engineering [7]. We have never been so close to achieving these technologies as today, especially by the tools of the new sciences, as the tissue engineering. In which mechanical engineering needs to be attentive and update itself in new themes. Making a three-dimensional printer, however technological it may be, does not come close to $1 \%$ of what is needed. It is necessary to go beyond, to join the technologies of automatic DNA sequencers, software's, complete interfaces, biomechanisms, and an in-depth tissue engineering study. Which is the reason a mechanical engineer does not have a tissue engineering discipline in his grade? At manipulating genes level, and even working with PCR, HPLC and iPSC with its triggers and even genomics manipulations by CRISPR. And this paper tries to be a first call for mechanical and chemical engineers to invest in biosciences interfaces.

\section{General Description about This Study}

This paper attempts to present bioscience from the standpoint of mechanical engineering for popularization and adoption as new issue and concepts through discussion, experiment and examples as a means of simplifying and standardizing the use of these biosciences' practices by other disciplines for the benefit of tissue engineering. Discuss the stem cell differentiation by interaction between 
tissues and external environment. Also, discussing about the communication system internal, superficial and external by cells, and the high potential in mechanism of integrin and actomyosin. In a trial to connect interdisciplinarities with affinities and interfaces with the iPSCs - (induced pluripotent stem cells), its connections with the environment and tissues as control keys. In the initial attempt to classify items with common affinities between mechanical engineering and tissue engineering. This complex matrix study resulted in the number of variables involved, trying to expose the practical applications. So that engineers from other fields, in addition to bioscience, can bring their contribution to this field of nanoscience. The importance of clearly listing and organizing the already known the stem cell activation mechanisms, so that they generate specialized tissues. Which it can range from a tooth to a specialized surface area, such as the microvilli of the stomach. It is vital, to understanding the possible lack of control that occurs in stem cells [4]. These stem cell activation keys can be a chemical reaction, a synthesis, an enzyme, a nucleic acid, the specific nanotopography support for stem cells [2], a specific ideal condition of temperature, pressure or physical chemical reactions, several other activation keys, including malformation, and poor connections between vessels and cells. The stem cells keys or triggers start by: progenitor pool, FGF-2, PDGF, EGF, followed by: angiogenesis, osteogenesis, chondrogenesis, adipogenesis and myogenesis. Then, some known keys are listed as: VEGF, BMP-2, Osx, PDGF, EGF. Wnts, Sox9, N-Cadherin, PDGF, C/EBP, MRFs, MEF2. Finally, resulting in: endothelial cells, Osteoblasts, Chondrocyte, Adipocyte and Myocyte [1]. A discipline with infinite variables, something ideal to be studied by data intelligence, programming logic, and with this bioscience's information and the analytical mechanical engineering can being reactivated and contribute immensely with the tissue engineering. Important to consider the orderly, classified and clear knowledge of these keys is a valuable tool for tissue engineering. There is a diversification in the subjects dealt with in this purposeful and necessary study. The main objective is to understand this biological matrix about the tissues ability to converse with the environment, thus creating a complex interface between the nucleic acid logic and the external environment as the main mechanism for provoking the evolution of species [10]. By activating keys and triggers in both adult and new stem cells [15]. Biosciences to have this knowledge in a complete form, and mechanical engineers who can design new CAD/CAM precision applications, as for bioink in vivo deposition equipment. With additions such as pick-and-place for manipulate biological artificial tissue parts for medical applications, such as a precision tailor. High-level in logic and mathematics is vital for the biological variables' manipulation, through analytical data of physical mechanical engineering. For this reason, interdisciplinarity is defended in this study. Thus, there must be mechanical engineering working with biochemistry, as well as the search for interfaces between computation and biological mechanisms, for the generation of high-level technologies. For the biological clusters assembly [14], complex natural control mechanisms such as those involved in nanotopography, e.g. integrin, actomyosin, and other mechanism for superficial area uses. As well as knowledge of other triggers for nanotopography uses, such as a compatible understanding in biochemistry principles, and the main mechanisms of induction and stem cells nutrition.

\section{Methods}

The strategy to the idea in the method was to use HPLC to separate the old DNA from the new fragments. After the extraction and denaturation performed by liquid chromatography for comparison between the newer genes. Then was searched for possible indices of outlier mutation using math statistics. Also, analyzed the sequence, compared with standard sequencing tables, observing chromosomes 4 and 20, but was studied especially the $\mathrm{MC1R}$ pigeon gene.

\subsection{Objectives Aimed for Investigation and Breakthroughs}

The questions that this paper tries to answer consider the topics related to the identification means for programming and reprogramming specialized cells by iPSCs in an automated way making analytical engineering uses and integrin interfaces by innovative engineered scaffolds geometries for nanotopography. Also, the idea of popularizing for other disciplines tissue engineering, and the classification of the main keys of activation specialized stem cells. Through control by engineering means in the iPSCs of specialized cells for tissue engineering. Comparisons of strange cases such as teratoma that is a germination disorder, something like there was no correct recording in genes, in addition to other cases in the understanding of the healthy development of stem cells. Comparative studies on mechanical engineering, programming logic and printer suggestions specific to each case, using the building materials themselves as the scaffold use as a structural element and as a biological deposition printer at the same time. As well as the variables ordering by logic, for the mechanical control of organic formations, in a scientific, mechanical and computational biological interface. Mainly for understanding the control of the integrin mechanism and its interfaces and communication with the internal and external environment, as a learning element and specialization. From these concepts it was possible to carry out an experiment that will be presented throughout this paper, and case studies to investigate the applications with mechanical engineering in 
tissue engineering. Through the results it will be possible to generate tables and references for later uses. Also, a better comprehension about the interfaces between the internal cells, the tissues and fluids, which is the main-focus of this study. The possible interfaces for mechanical engineering and tissue engineering for new technologies. The organic geometry importance, the available space use and its distribution by opportunism to work with in vivo paint. Studies on low pressure vascularization and biological mechanisms involved in microfluidics. Popularize the biosciences to leverage complexity involving large random variables volumes and thereby gain processes control and thus solve problems, using some concepts from computation as showed in [11].

\subsection{Preliminary Results - An Overview}

One of the main points aimed of this study was the search for the interfaces between the environment and the iPSCs, stem cells or cells already mature, and the environment, e.g. the excess of UV in biologic tissues as inducting possible less melanoma. The result that the external environment and internal factors are the main agent in the health and evolution development cells. So, for a perfect nanotopography control a suggestion is about the better comprehension about integrin communication mechanisms between cell membrane with the internal and external environment. This interfaces in nanotopography are taken by direct contact interaction into the cells, changes are caused by external stimuli, and through complex interfaces the integrin getting this information for cell. In the case of stem cells integrin are vital for specialized tissues formations, as well as for interference in old cells. In some cases, external interferences can cause changes in development new tissues. The more stimulated, the more they activate and perfect themselves the neurons/brain. When we compare iPSCs with a virgin hardware for information storage, we have recorded the data according to the external stimuli of the environment. Or even compare it with the brain a newborn to which it will develop from according to the environment that is inserted, e.g. if this newborn is created in a neutral environment, such as a desert island, without contact with any communication there will be limitations to it. Its development and more neurons generation will be limited. Different from a newborn in the information age. The iPSCs can turn any specialized tissue of a body, e.g. a tooth, a hair follicle, a bone cell, muscle, depending on external or internal stimuli and ideal conditions. A suggestion is that the genes in focus internal to these stem cells when undergoing external stimuli, physicochemical contact and interaction, by nanotopography or others, proves that stem cells, as well as the development of a brain of newborn, is dependent on the external. Environmental stimulus having control of these processes it is possible to create machines for this purpose, to manufacture synthetic biological tissues.
Thus, the external stimuli, by complexes interfaces, passing by integrin or actomyosin can activate some specific gene, causing a specie evolution in some specialized tissue. If the external stimulus has a frequency or is vital for some specialization, keeping the rest inactive. Something like high-performance hardware used by a person who only uses it for simple functions, compared to a person who uses the same hardware at its limit, for high performance analytical simulations e.g. rendering and analytics, consuming its full processing limit. In this way, knowing that genes act by external and internal stimuli conditions. And by an engineering view, if possibly gets the knowledge, cataloguing and control of these activation keys will be possible new applications. The very evolution of species demonstrates the specialization of each being according to the environment for adaptation. From the diverse studies, such as those more popular as presented in the Discovery ${ }^{\mathrm{TM}}$-The mutant planet series, them as by reference [19]. So, we clearly observe several examples of adaptation and very sophisticated specializations, which shows a possible external environment interface between tissues by integrin cell to membranes and to the genes [22]. Cases like crawling birds like Apteryx that adapted in the soil, where there was more food, cancelling the evolution of the wings. Through the contribution of external stimuli of having no predators in the soil. The environmental factor and its direct communication with tissues are evidenced e.g. as by the interface between the eyes and the interior of the organism. The case of animals held in cages for a long time, e.g. as observed in popular markets in China and other countries that sell live animals for consumption, there is a high degree of neurological problems. Because, the environmental stress and deprivation of liberty, including muscular atrophy, uric acid accumulation in the tissues and other unique characteristics that do not match the ideal conditions to which that organism was adapted. These examples are ideas for a better understanding of the importance of external stimuli in control of specialized stem cells.

\subsection{Study by the Pigeonhole Analysis for Evolution Species Induced or Forced}

Details for a preliminary study of the monitoring biologic communication between the environmental, tissues, iPSCs and the genes. The biology generates an eternal improvement system complete by complex communication interfaces that are getting better over time. This communication interface is the real motor of natural evolution. The tissues work as sensor reading and in communication to read the environmental. So, for this paper some tests have been carried out on plants and animals, e.g. in pigeons, it is possible to completely change the characteristics of a pigeon. To the point of being totally different from its original breed, through crosses, hormone ingestion, genetic editing and the environment changes 
[20]. In this way, was studied one pigeon by a long time, and observed the changes by induction. Recent study too demonstrate that the urban environment is inducting some evolutions or adaptations in urban animals [19]. In Table 1 we can see a study of correlations between the measurements of a pigeon's body - proving by the internal anthropometry change by time: A change is occurring in some animals around the world. This paper tries initiate this comprehension by communicating and reading the external environment by tissues. In this study, carried out with pigeons, the initial measurements of one pigeon is presented.

Table 1. Studied spare-parts in the pigeon and observed possible effects by MC1R gene in colours and other observations, as zoometry, conform showed in this table.

\begin{tabular}{|c|c|c|c|c|c|c|c|c|c|c|c|c|c|}
\hline $\begin{array}{c}\text { Age } \\
\text { (years) }\end{array}$ & $\begin{array}{c}\text { Weight } \\
\text { (pounds) }\end{array}$ & $\begin{array}{c}\text { Height } \\
\text { (inches) }\end{array}$ & $\begin{array}{c}\text { Neck } \\
(\mathrm{mm})\end{array}$ & $\begin{array}{c}\text { Thorax } \\
(\mathrm{mm})\end{array}$ & $\begin{array}{c}\text { Abdomen } \\
(\mathrm{mm})\end{array}$ & $\begin{array}{c}\text { Legs } \\
(\mathrm{mm})\end{array}$ & $\begin{array}{c}\text { Thighs } \\
(\mathrm{mm})\end{array}$ & $\begin{array}{c}\text { Knees } \\
(\mathrm{mm})\end{array}$ & $\begin{array}{c}\text { Feather } \\
(\mathrm{mm})\end{array}$ & $\begin{array}{c}\text { Wings } \\
(\mathrm{mm})\end{array}$ & $\begin{array}{c}\text { Forearm } \\
(\mathrm{mm})\end{array}$ & $\begin{array}{c}\text { Tail } \\
(\mathrm{mm})\end{array}$ & $\begin{array}{c}\text { Body } \\
\text { fat } \%\end{array}$ \\
\hline 5 & 0.458 & 4.99 & 20 & 14 & 46.6 & 50.1 & 30.2 & 10,2 & 90 & 190 & 180 & 100.6 & 4.5 \\
\hline
\end{tabular}

Data listing concerning pigeon's measurements zoometry by three years. In this study, these 13 measures collected in pigeon studied along three years, some have significant correlations, and some do not. Note that these measures are estimated the study can be improved by MRI combined with HPLC. Used as exemplification of the idea and the method intended.

The corresponding analysis mapping shows that the circumferences of the neck and abdomen of the pigeons have more close and strong linear correlation $(r=0.5467)$. Presenting small zoometric possible changes. An indication for possible induced species evolution. The idea now is to apply the concepts discussed throughout this paper in these results to try suggests the environment stimuli in communication with tissues in the change species.

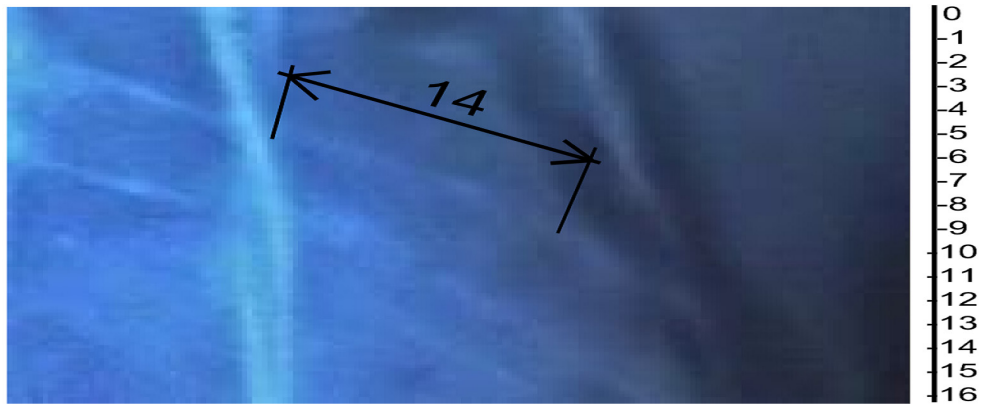

Image 1. X-Ray thorax pigeon part measured as $14 \mathrm{~mm}$.

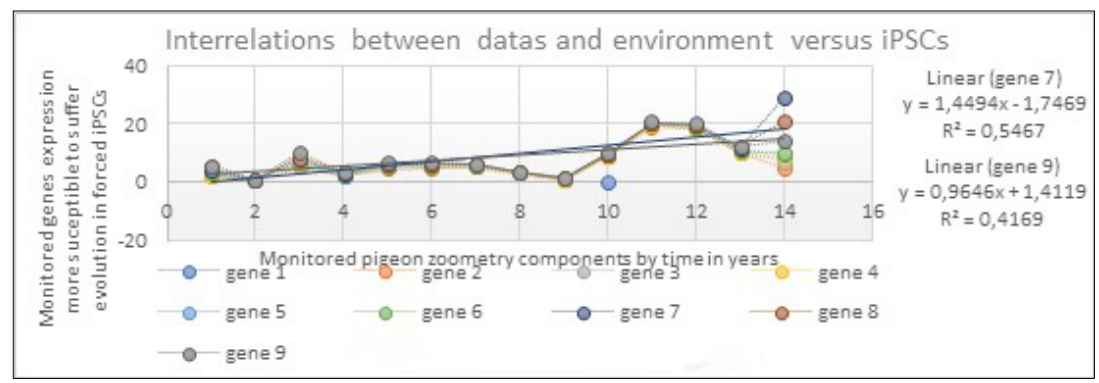

Graphic 1. Study of the interrelation and interpolation between collections of two or more related data that are the possible causes changes in biological natural processes. Was used the same gene, but in 9 procedures along the study.

Aimed the resulting in biological forced evolution in natural organisms, in this study was considered the pigeons as a model study. Considering their alteration and adaptive biological evolution by the forced change in the genes because of the new environment created by the humans. This suggests a possible interface and connection from genes to tissues and senses, to read the new environments, and forcing or inducing in the gene's mechanism to new adaptations. In the future, this study methods could be used for monitoring anthropometrics for human, and zoothropometrics for animals, so to monitor which modern life cause in the biology. All this used for measurements of the body in some pigeons, tampered with by pigeon breeders. The intention is to verify the possibility of forcing biological evolutions in the bodies of animals, to be applied in human beings. Thus, we can see in the data presented in the graph wide diversification measures, and a tendency to non-standardization, because the $\mathrm{R}^{2}$ closest to 1 indicates the most susceptible gene to keep its stability. An evolution in the human senses, which nature would take centuries to make, could be done in a short time. It makes possible a better understanding of the formation of the tissues and consequently improving the understanding for the generation of artificial tissues. 


\section{Functionalized Mechanical Nanotopography - As a Key/Trigger's Activator}

Focus the importance of analytical mechanical engineering in the discipline of tissue engineering as a complement, especially for biological analytical mechanisms in superficial area. And by this way adding disciplines of the mechanical engineering as an analytical study of an engine, including: machine elements, structural components, mechanisms that control movements, components and operational interface. The main point is that after familiarizing the common terms in genetics, biology and other life sciences. So, the mechanical engineer will be able to collaborate a lot with complex analysis, especially structural and analytical for tissue engineering. What this suggests is that in vitro culture conditions should be explored in greater depth to gain a deeper understanding of the cellular response for use the nanotopography. The mechanical nanotopography as a key/trigger's stem cells activator. Such knowledge would have the potential to enhance the utility nanotopography efficacy in translational research. Including the new tools that can be unified with the tissue engineering, look in table 2.

Table 2. The expansion, comparison and high power of the new interfaces with new sciences and possible unions [21]. A study of interdisciplinarity about subject's compatibles. For these estimated values was considered the analysis in 60 comparative studies with interdisciplinarity.

\begin{tabular}{|c|c|c|}
\hline \multicolumn{3}{|c|}{$\begin{array}{c}\text { Focusing the nanotechnology and biology in comparison with some } \\
\text { variables to find compatibilities to new tissue engineering tools. }\end{array}$} \\
\hline Parameter interdisciplinarity & Interfaces & $\begin{array}{c}\text { Compatibility } \\
\text { level }\end{array}$ \\
\hline Analytical mechanical & low & $33 \%$ \\
engineering & high & $24 \%$ \\
Data science & average & $15 \%$ \\
Electronic technology & high & $16 \%$ \\
Nanotechnology & low & $12 \%$ \\
Combined technologies & \\
\hline
\end{tabular}

As the same way works in vitro automatize it by mechanical engineering analytical e characterization. The idea is to generate analytical, biological tissue engineering equipment for in vivo bench simulation, e.g. a tissue / system that grows and behaves as a specific specialized tissue. But in a $100 \%$ controlled system, in vitro with interfaces that simulate the reality, so that this system is assisted computationally. One of the alternatives for working with artificial tissues by analytical mechanical engineering would be the use of pick-it-and-place type picking machines to pick up small squares of artificial tissues and allocate them on an organic scaffold. Making use of computational logic and specialized mathematical matrices three-dimensional. A technology to the model of specialization packages by geometric organic matrices. "Faced with this suggested possibility, a vital theme is nanotopography, following the concept of modern bioscience that consists of a shift in focus from the molecular biology tendency to a concentrated one. This contemplates how these molecules interact with one another to form condensed modules that act as discrete functional systems." By these approaches we may consider more focused means, thus prioritizing stem cells as a means for popularizing its domain, e.g. [12], already by a genetic engineering approach. There are very simple didactic techniques that make detergent use and other disintegrating solution [6], as in the case to destroying the nucleus of cells, where there is the organization of nucleic acid. Experiments that can break the cell membrane and releasing the nucleic acid chains in the fluid, resulting in a kind of white wires destroying the organization. However, getting to this entropy is easy, like breaking a glass. The question and difficulty are in the opposite, that is, reaching a control, or an enthalpy that would be order and organization synthesis. So, the genome project has been working on sequencing. However, what can come to the organization is the work of several teams through alternative techniques that consists in understanding the organization of nucleic acid chains, and the DNA in 3D by sequencing [9], [16] and methodologies and practices use as including CRISPR for a precise synthesis.

\section{Discussion and Details around-A Needed Interdisciplinarity}

For a complete understanding of the subjects treated follows a discussion with the main variables involved. To know well the stem cells mechanism, factors, keys and activation triggers in the iPSCs that will define in advance the destiny of the artificial tissue. And to have that control is the triumph in tissue engineering, its adaptation flexibility is important. Therefore, practical applications should not be neglected by the importance of the multidisciplinary set of sciences use in open platform and the mechanical/chemical engineering point of view. By studying the behaviour of the stem cell mechanism, including theories that involve the nucleic acid mechanism. Considering for this the theory evolution of species [18], in addition to intelligent scientific design [17]. Although intelligent design is scientifically discredited, it could somehow being understood as something virtual, e.g. how the subjectivities of living beings act in biological bodies. In other words, anger, hatred, nervousness, stress, scientifically causing high blood pressure, raising or lowering heart pressure, raising or lowering body temperature, and all this tends to change the mechanism biological bodies. And subjectivities are directly linked to the environment to which the living being dwells. In this case, subjectivities do have a role capable of triggering specific stem cells, as well as bringing certain information to the genes. Something not easily noticeable, e.g. how complex the mechanics of processing information by neurons, but fully explainable by physics. Including the 
virtual function that occurs in physical means, e.g. the communication, reading and interpretation that occurs in the proteins does of the environment and its needs by the human senses. In the same way that vision, hearing, touch, thermal sensation, subjective feelings bring information to the brain, and make the neurons smarter, the external environment also causes changes in pressure and heart. The genes in this way, by electrical, biophysical-chemical communications also can read, interpret and decode the environment, resulting in a complex network of biochemical means of communication, and even activating keys for adult stem cells [15]. This being the trigger of the evolution, or adaptation of species strategy. Examples are the living beings that can regenerate by their own biological abilities when reading the recorded DNA-information chains [3] by communication in complex interfaces, so commands can activate stem cells, for generate species evolution. The regeneration of the salamanders for serious damage, the tail of the gecko that is reborn, earthworm, living water that even performs the generation of the new individuals. In addition to regeneration cuts, wounds, scratches on humans and other animals that has great capacity for regeneration. Calling attention to adult cells that can also undergo changes, or even induce changes by communication, interfaces and interpretation of the environment [15]. All this induces something like hardware that holds out the constructive information of that being, or specific parts. The database-in genes are a programmable biologic system, the control of this process will guarantee tissue regeneration. However, to get the domain of this complex system is necessary some analytical engineering practical applications and apparatus. As doing growing defective artificial tissues, as teratoma in vitro, by computer assisted systems. For a better comprehension of the control in iPSCs, is only by genes or too in other factors? By complex biochemical interactions between cells and environment? Within these defined concepts, and with an interface visualized, with the analytical logic application. It becomes possible to program and reprogram the biology of the stem cells, even after already formed, and with this objective reached the consequent control of this biological mechanism. In figure 1 there is a proposed model for generating defective biological tissues, practically a teratoma factory. For understanding and listing possible errors that make this occur naturally, for future documentation and improvements in processes producing healthy or illness artificial tissues by disease-in-a-dish concept.

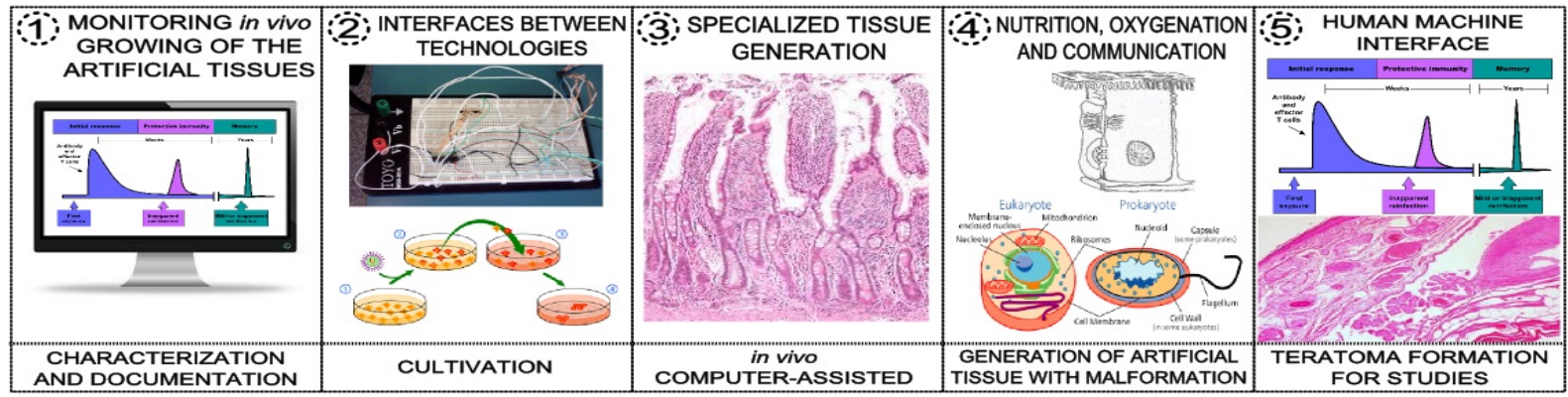

Illustration 1. Sequencing of a model to generate defective artificial tissues assisted by computation - A computer program for assisted teratoma manufacture. By dominium of the malformation will come an important knows in the control in tissue engineering. Because this study also advocates the study to dominate the diseases formation and not just cure.

The steps from 1 to 5 in the illustration show a schematic apparatus for formation and monitoring the diseased tissues growth, assisted by analytical computation. Without the need for the use of living beings, this device will be able to work the iPSCs on the bench, more effectively. Enabling more people to access to this study, due to the low implementation cost by concepts as the disease in a dish and lab-on-chip platforms. The idea is based on the principle that by mastering the understanding of the malformation causes we will have control in tissue engineering. This computer-aided biological analytical apparatus has the advantage of working within interfaces that are difficult to visualize. To include communication between cells, and in units of difficult reach $(\mathrm{nm}),(\mu \mathrm{m}),(\AA),(\mathrm{Hz}),(\mathrm{pN}),($ Siemens), $(\mathrm{fs}),(\mathrm{eV})$, and interconnecting the biological tissues logics. The need for the logical domain in the control of stem-cell programming is understood. The stem cell if viewed from the point of view in programming logic is an agent to high potentiality in work with biosensors and interfaces. The stem cells are programmable and reprogrammable, while taking new gene advantage editing tools. And mainly, considering mechanization techniques and biological automation much used in mechanical engineering [5]. To achieve an analytical mechanical for stem cells, control and for their biomechanism. It is also interesting to consider the studies concerning the nanoparticle control logics [13], [14] for a possible partnership in biosciences. And by applying logic in this potentiality with the full knowledge of the keys and triggers to properly induce the stem cell to become the desired tissue. Through the complication that this induced cell is allocated in the correct place and integrates in the middle, taking the natural cycle in its function, e.g. irrigation and nutrition. In this alignment, we can present some configurations in the search for alternative means to work with this biological material with refined logic and analytical mechanics. 


\section{Keys activation Embryonic Stem Cells in the Biological Evolutionary Triggers Mechanism}

The external and internal keys and stimuli that activate the iPSCs induced pluripotent stem cells, and their mechanisms, to generate specific tissues. It is the principle for mastery in this bioscience engineering. As an example, external stimuli carried by human sensations, such as vision, taste, smell, pain, thermal sensation and even subjective. They are external stimuli that can induce and activate triggers, captured by diverse means, like eyes, skin, touch, ear, and from this interface these stimuli arrive the cells, and consequently the gene. Another example is the eyes that bring information to the neurons, and according to neurological research, the more stimuli, the more connections are generated and the more neurons. Something like a person who does not practice exercises often versus a sedentary person, therefore, the person who does not practice exercises tends not to develop so much his organism. The brain and gene are dependent on external stimuli as well as tissues. Like a computer, its capacity for processing, recording information, programming, processing and reprogramming depends on its use and
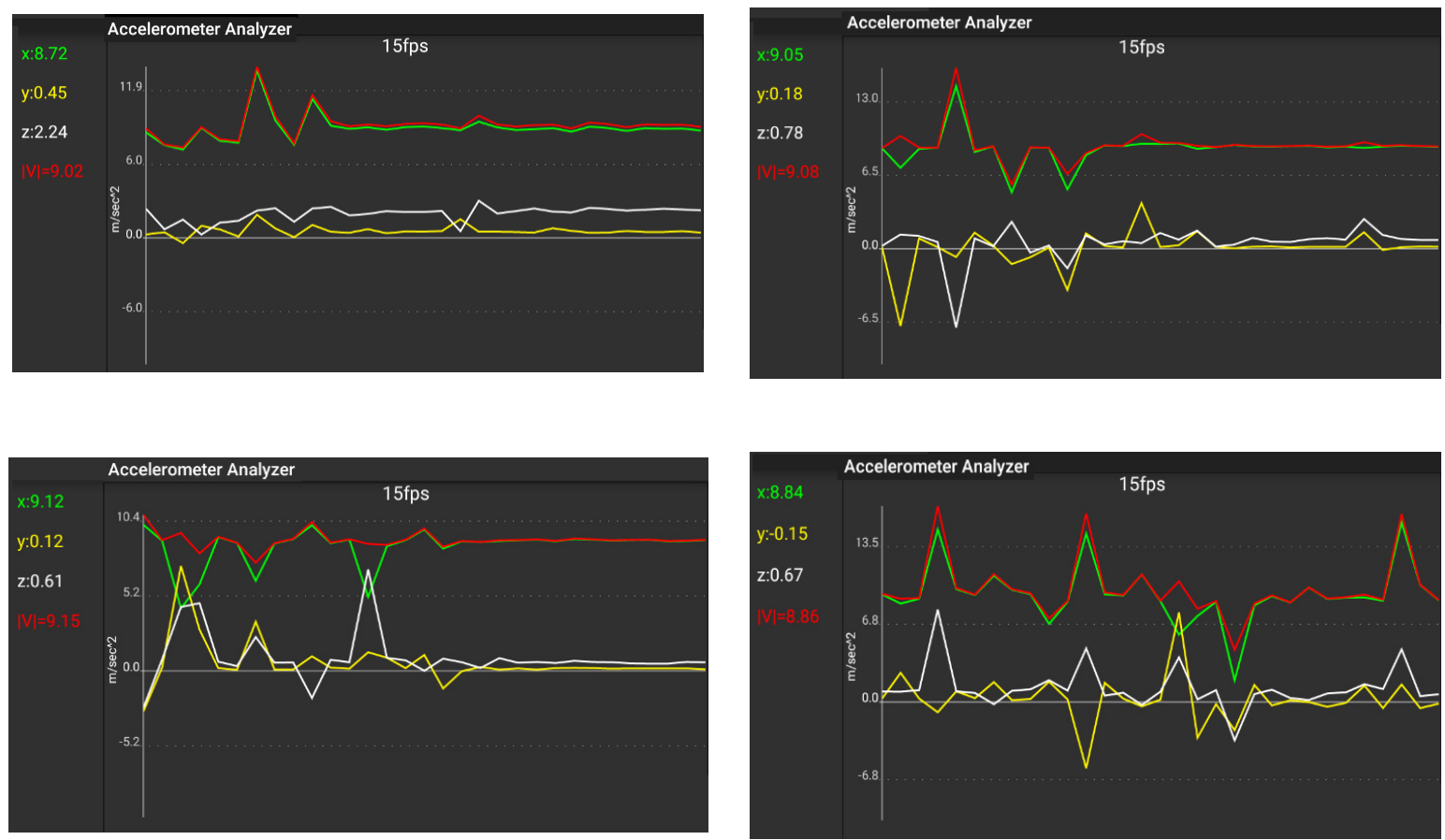

Sequence 1. Representation of the vibration by MHs during the embryonic gemination for study the subtle environment interference along the critical and the delicate germination procedure.

Was used the analytic instrumentation: accelerometer Analyser ${ }^{\mathrm{TM}}$ connected in a sensible blade with the germinative tissue in development to measure the induced vibration. It is an experiment to study the human interference effects on nature. The methodology used consider a germinative sample unit exposed to noises and vibrations, and another one under ideal germinative conditions. Although both samples had developed, the one on stress had a subtle but minor development. This could suggest a means of stimulating some evolution or even tissue damage by tissue malformation. There are strong indications that human interference with the natural environment, interfering with ideal living conditions 
in natural environments, tends to cause evolution in many animals, as well as tissue damage yet unknown. The table 3 shows some possible activation triggers for germ cells and general units used.

Table 3. Activation factors, combinations and variables that define the type of specialized tissue to which the stem cell will become. See too some examples of the various transcription factors combinations and cell types that can be used in the iPSCs/ESCs embryonic stem cell production. With special attention for gene Oct4 and Sox2 - in table 1 from [1].

\begin{tabular}{|c|c|c|c|c|c|c|}
\hline NAME & $\begin{array}{c}\text { DESCRIPTION } \\
\text { EXTERNAL STIMULATIONS }\end{array}$ & $\begin{array}{l}\text { ACTIVATOR } \\
\text { EFFECTS }\end{array}$ & $\begin{array}{c}\text { KEYs } \\
\text { TRIGGERS }\end{array}$ & $\begin{array}{l}\text { COMMOM } \\
\text { UNITS }\end{array}$ & $\begin{array}{l}\text { SPECIALIZED } \\
\text { TISSUE }\end{array}$ & FONT \\
\hline A & Activates the stem cell by contact & $\begin{array}{l}\text { Nanotopography } \\
\text { Mechanical }\end{array}$ & $\begin{array}{l}\text { VEGF - BMP-2 } \\
\text { Osx - PDGF }\end{array}$ & $\begin{array}{c}\mathrm{Nm} \text { and } \mathrm{A} \\
\mathrm{Hz}\end{array}$ & Soft tissues & [2] \\
\hline B & Active by synthesis reaction & Biochemistry & EGF. Wnts & $\mathrm{pN}$ & Hard tissues & [2] \\
\hline $\mathrm{C}$ & Active through external reaction & Phisical-Chemical & $\begin{array}{c}\text { Sox9 - } \\
\text { N-Cadherin }\end{array}$ & $\begin{array}{l}\text { Siemens } \\
\text { fs }\end{array}$ & $\begin{array}{l}\text { Transport fluids } \\
\text { Nutrition fluids }\end{array}$ & [2] \\
\hline $\mathrm{D}$ & $\begin{array}{l}\text { Electrical reactions by ions and } \\
\text { electrons }\end{array}$ & Electric & $\begin{array}{l}\text { PDGF - C/EBP } \\
\text { MRFs - MEF2 }\end{array}$ & $\mathrm{eV}$ & Specialty tissues & [2] \\
\hline
\end{tabular}

The general objective of this study is to locate, identify and characterize the main means of inducing iPSCs. More precisely, the keys internal and external as triggers stem cell specialization. Here was studied the communication between cells and tissues, the interaction and interface between genes and tissues already formed, along with diverse variables, such as fluids as a link between processes. Some basic technical details in tissue engineering contemplate understanding such things as the mechanism and communication system between cells, their life cycle, and mechanisms, e.g. how cells are held together, nourished and breathed, and how they transmit biochemical and other information. So, how the biological mechanisms and cycles operate, strategically for the production and scaffolds use, and the scaffold as inductor and key stem cells. Artificial tissue studies for basic knowledge about epithelial tissue, and teratoma as understanding the stem cell totipotent or iPSCs flow mechanism means for tissue engineering. The main terms and specificities in stem cells. Strategies and means of working with stem cells and case studies. Biological modelling and new digital systems. The interdisciplinarity and digital convergence required to modernize mechanical engineering to incorporate and contribute to tissue engineering [8]. For a patterning and customized biological modelling, to study the communication between cells on a micro/nanoscopic scale and on the involved bio-electrical and fluidic fluxes.

\section{The stem Cells and Biological Mechanism Comprehension - Due Control of This Mechanism}

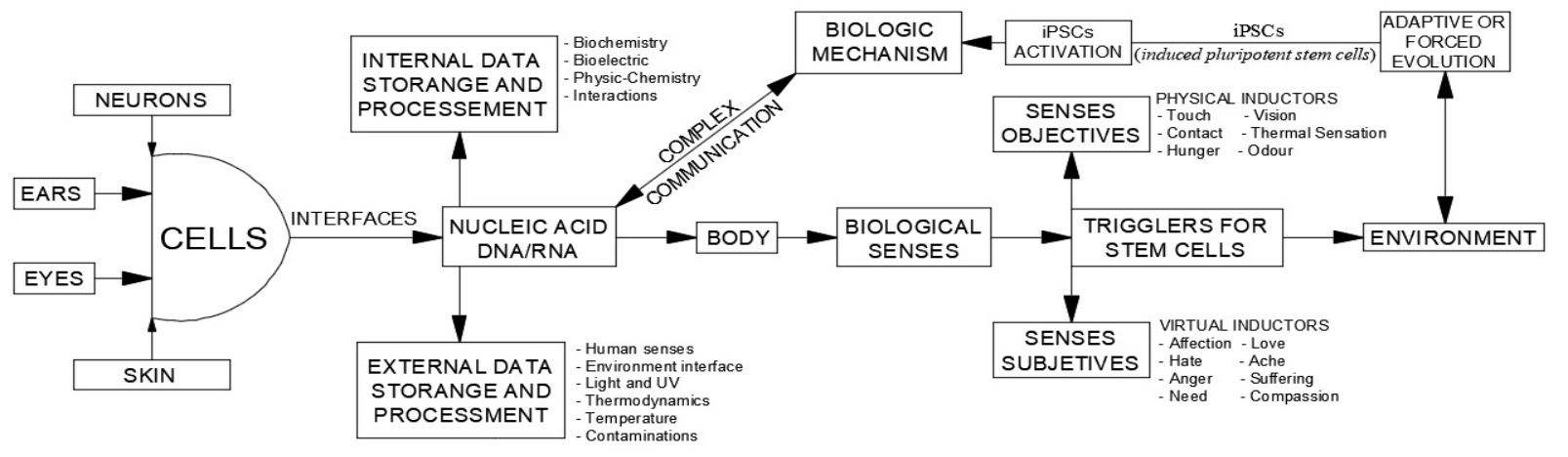

Fluxogram 1. A general view of the tissue interfaces mechanism with the environment and others possible inductors.

A complementary way in this study is to present ways to suggests that the tissues read the environment and based in specific factors can improve changes in the iPSCs. Focusing on this study defense, which is the communication of tissues and genes with the environment, as an activator of the induction stem cell totipotent cells mechanism to form specialized tissues to adapt to the needs of the living organism. The interface and communication tissues with the environment acts as a language, not yet completely understood by science, making complex codes use by various means. As a complex biochemist they interact between soft or hard tissues, fluidic tissues and even considering the subjectivities. Studies have already indicated that plants communicate by roots by odours and chemical [23]. In the case of mammal's genes has its interacting ways with the environment. The dominium of the transcription factor and all the biologic mechanism in stem cells by mechanical engineers by analytical and practical applications is a real potential to generate innovation for practical applications. The fluxogram $1 \mathrm{a}$ visualization of the main variables involved in the activation pluripotent stem cells processes. With the main 
activators of their capacities. The fluxogram try to present a first sketch for comprehension tissue interfaces with the environment.

Note that nanotopography and activation triggers occur more than in one dimensional border, including small measures, as angstroms and nanometers, virtually invisible to the naked eye. Just as by external, objective and even subjective influences, as a high stress environment will force some biochemical reaction on the tissues, forcing some reaction. Therefore, the iPSCs can differentiate virtually to any type of specialized tissue cell. And the control of these processes, whether virtual, objective and physical-chemical, are vital for these processes control. And one of the ways to characterize and analytic these mechanisms is in the diseases modelling, as well as the concept of diseases in a dish for modelling human genetic disorders using induced pluripotent cells for the principal trigger as Oct4 and Sox2, or chemical-physical activators.

Here a note for the importance to comprehend each part of the human body, for a dominium of the iPSCs, as well as comprehend that just $\sim 2 \%$ adult cells have pluripotency as iPSCs, considering too other potential germinative cells. An in-depth knowledge each part of the human body is made important by future applications means. With this identification and a specification with a complete characterization of each component of the body it is possible to apply analytical mechanical engineering techniques to automate tissue engineering. As example the procedures of the traditional mechanical engineer, to produce analytical machines. In fact, there are already several interfaces examples and interdisciplinary linking working with biosciences, e.g. automatic DNA sequencing equipment. However, is important consider that it is necessary to take current knowledge out of the box. Something besides exposing the already known in a brainstorm, that is, taking what is already known about biosciences to the knowledge of other disciplines, as for that mechanical analytical engineering. So, as consider the studies in analytical projects, as a reference to the advance in automation that undergo tissue engineering. Faced with modern bioscience and computation, it is necessary to recover the old complex mechanical sense methods, based on many abstract variables to be ordered, in functions, objectives and finally mechanized. Recalling typewriters and recorders, in their analytical mechanics led to computers in the future. Based on the interface between humans and these machines, to start now in this biological interface. Then, include experiments that mimic the processing mechanism, storage information made by DNA - amino acids, as a true natural biological computation, to the biological circuit dominium.

\section{Nanotopography as a Pathway to Induct Stem Cells Specialized Tissue Formation - A practical analytical study}

Over all the variable points involves the keys that activate the stem cells, and control the development, that is, the keys that induce the cells to specialize in specific tissues. The most important point to automate and mechanize biology with analytics automation. The control of the programming cells together with mechanical interfaces and programming logic is the proposal of this work. In an in vivo experiment, when placed by gravity and direct contact cells randomly arranged in a petri dish, as shown in illustration 2, e.g. the junction was checked for accumulation and contact. This is a suggestion for automate analyte with Oct4, Sox2, Klf4 and c-Myc.
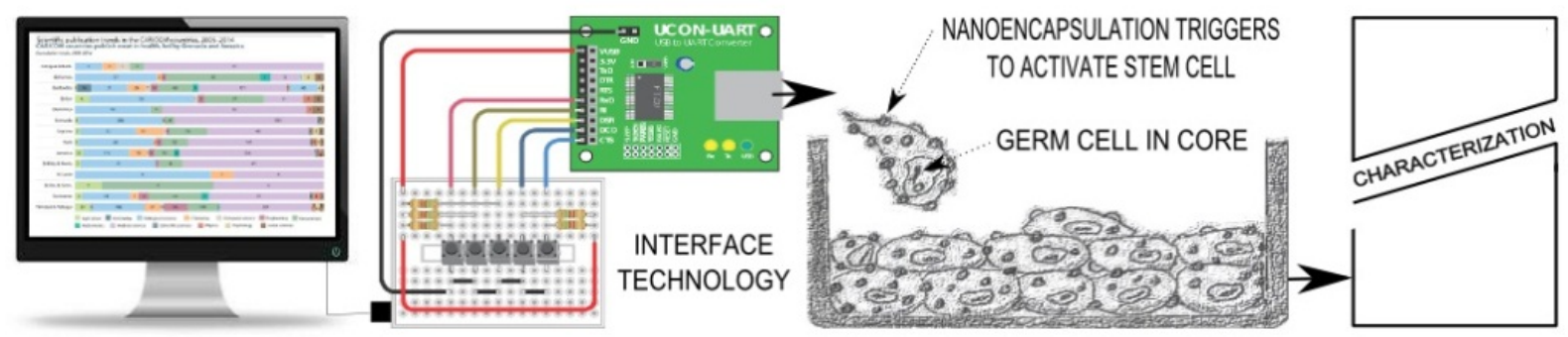

Illustration 2. Experiment for use some principles in vivo ink drops with nanoencapsulation triggers and in core each drop a stem cell. This is a simulation for automate scaffolds as auto-supported biologically.

In this experiment was studied the capillarity, gravity, contact induction, weak physical/chemical bonding, as van Der Walls and ways to activate individually. This is a suggestion for automated disease-in-a-dish for studies, lab-on-chip deposit iPSCs in a base.

This steps sequence shows us the possible interfaces between biological, digital and mechanical steps to produce real documentation about these studies. Controlling automated and scanned stem cell activation keys is only one step in total tissue engineering control. It is also necessary a domain in biological mechanics, e.g. in the epithelial tissue formation its mechanisms and flows, as well as processes such as mitosis, meiosis, anaerobes beyond a list of biologic processes, too considering the fluidic issue as capillarity and physicochemical issues involved, as pressure and temperature ideal. Understanding these interactions by practical ways. Including external stimuli, stem cell activation keys, biochemical 
triggers, interaction of the chemical energy, electrolysis and various exchanges in $\mathrm{eV}$ and other nutrition and communication fluids. In general, some interactions between physical biology and the environment in all stimuli are not visible that perhaps theoretically explained by approximations and comparations.
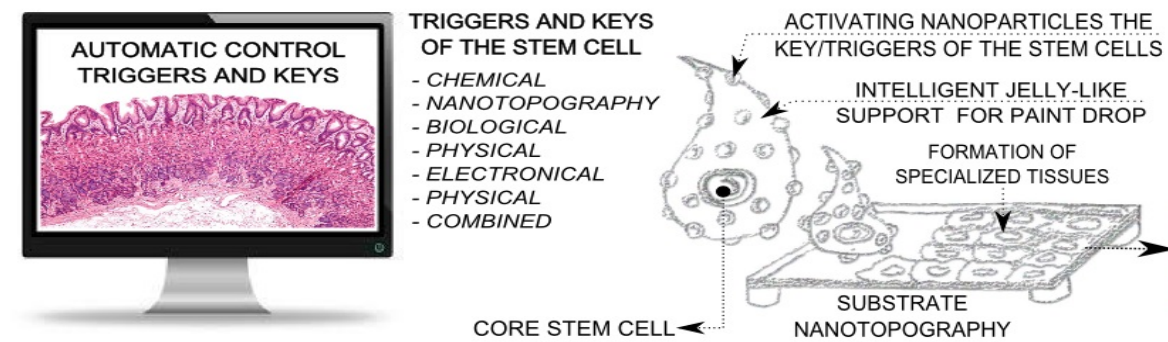

NANOTOPOGRAPHY SUPPORT SCAFFOLD FOR DETERMINE ITS LINEAGE SPECIFICATION

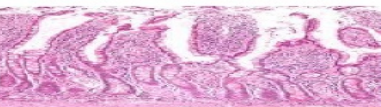

SPECIALIZED TISSUE IN FORMATION

Illustration 3. The encapsulation of the processes by the engineering, like the ink drop functionalized in vivo in activating fluid capsules for the stem cell, in special to observe the integrin mechanism in vivo.

\section{Scaffold Functionalized-Activation Mechanisms for Determine Specialization Tissues}

In tissue engineering a major point is in the domain and control of the ideal conditions to activate at the right time and in the right place the cells. The scaffolds use as in vivo ink depositor printers is suggested, and at the same time as an activating means for stem-cell keys and as a structural element for the formation of specific tissues. One technology suggested in this paper for practical application of the concepts treated throughout these studies is in vivo ink, a mechanically and biologically functionalized smart ink by pharm nanoparticle. See illustration 3. The functionalized scaffold as a structural element of irrigation and stimulation, to activate the key stem cells. The variables control involved in tissue engineering must occur through complex communications of interfaces between subjects. nanotopographic, electrical, physico-chemical and other triggers and previously classified keys. In the illustration we can see the process with use of bio ink with triggers in nanoencapsulation

When one of these keys is activated, it is attached to the stem cell and activates its functionalization by direct contact or mechanical interaction. This approach has suggestive purpose practical application of some of the concepts discussed throughout this paper, so that the paper is end-to-end, so as not to address only conceptual purism, but also to contemplate practical application. In this way, we intend to present the approach by mechanical analytical engineering and mathematical use. The scaffolding and ink functionalized with nanoparticles as a deposition, structural and deposition element is one of the proposals of this paper. However, to get to this control and mastery a classification, functionalization and events list, including pharmaceuticals is necessary. Therefore, the scaffolding should be much more than just structure, but acting too as a feed in the scaffold structure, but too as dynamics process accesses by the structure. Throughout the paper will be presented this proposal and the influence of the external environment on the tissues and genes. And the importance of the know-how of mechanical engineering and analytical electronics in this way, after due classification of the variables involved and their due technical understanding, e.g. to have the technical domain of the stem cells full cycle, and the major triggers of activation, as e.g. a better control in integrin and actomyosin.

\section{Dynamic in vivo Scaffolds}

Other important consideration was percussed by generation concept of a dynamic scaffold, an automated assembly, biologically self-sustaining.

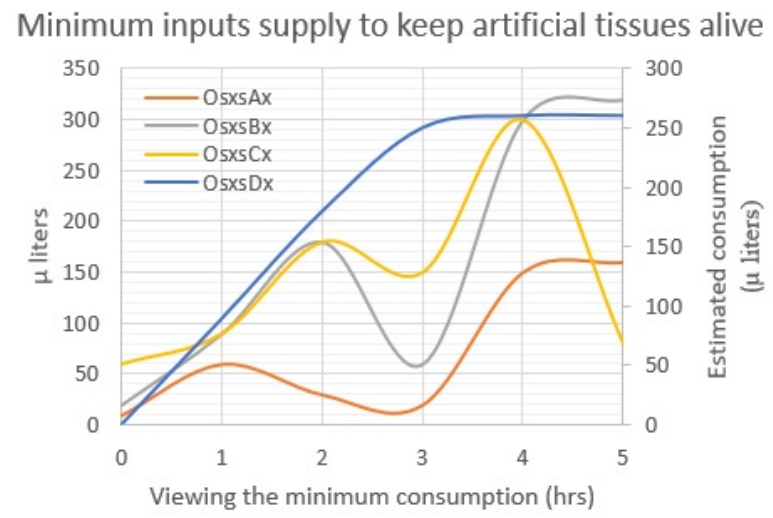

Graphic 2. Lines plots representing the minimal supply for keep life. Including oxygen, water, nutrients and ideal environment. Anyone marked as Osx, representing the input.

The idea is to generate specialized artificial tissues by the lab-on-chip or in-dish process, or even on scaffold platforms functionalized with irrigation microchannels. And just as you apply serum and nutrients to venous patients, you will nourish these artificial tissues and note down the ideal consequences and quantities. The purpose would be in the future to generate normative calculations to feed the future machines for biological tissues manufacture with the correct mathematical units. Such minimum units to keep the tissues alive. 


\section{Final Remarks and Outlooks}

Throughout this study was presented the bioscience for mechanical and chemical engineers for its popularization. Through the idea of familiarizing the theme, including examples of possible applications. The iPSCs power with correct patterned use of the triggers as Oct4, Sox2, Klf4 and c-Myc and with some control through tissues communication with the environment was questioned along this study. For that, a set of strategic methods, as showed by pigeon study, and the possible changes in his body were studied. After induced changes in the natural environment, feeding and diverse logic ways to crossings germ cells. By examining zoometric measurements, minimal changes were seen in some individuals. Was obtained initially a modest result, but that presented a way to be followed for more refined experiments. It was possible to suggest that the genes are programmable by the domain and knowledge of the correct keys control and activation of stem cells. So, the iPSCs, ESC's Embryonic stem cells as well as germ cells in general, focusing its specific triggers, e.g. Oct4, Sox2, Klf4, c-Myc, as others as physical or mechanical by nanotopography, can be influence the tissues specialization due to the external environment and internal or external triggers, e.g. integrin or actomyosin. Soon the stem cells are reprogrammable by the adaptation according to signals and triggers correct control of the internal or external environment, like the need of specialization.

The models studied sought to present possible practical applications to discuss the multidisciplinary concepts involved. Focusing on communication between cells, tissues and the external environment, including all possible mapped interfaces. The method used with pigeon helped to conclude that there was a slight zoometric pigeon, as model for futures anthropometric studies in the human body structure. Due to forced changes in the environment, feeding and germ cells crossing, or some manipulation by nanotopography for any trigger, as integrin it was possible to conclude that the tissues interacts and reads the environment biochemical signals. With the capacity to adapt the organism, activating, changing or cancelling stem cells possible adaptation. In the same way the eyes and ears carry information to the brain, the tissues read, interprets and adapts the stem cells according to the environment. This is possible by an interaction between a sequence of interfaces, starting from the genes to cell to tissues, using the integrin activation actomyosin, to read and interpret signals. Including specifics biochemical activation, as by nanotopography in the formation of specific tissues. With these results, it was concluded that it is possible to generate artificial tissues, with assisted growth in engineering mechanicals apparatuses. A way to reach new apparatus for possible automated control in biochemicals, with effective works with CRISPR, mechanical geometry studies for better scaffolds, genetic studies and the total control of triggers for stem cells. Therefore, it is possible to have control of changes in biological tissues, or even induce the evolution of species.

FINAL NOTES: Before use or experiments with iPSCs, is mandatory read carefully the procedures of the EBISCTM - Protocol for the use of induced pluripotent stem cells.

\section{Acknowledgements}

Financial \& competing for interest disclosure - The author has no relevant affiliation or financial involvement with any organization or entity with a financial interest in or financial conflict with the subject matter or materials discussed in the manuscript, including employment, consultancies, honoraria, stock ownership or options, expert testimony, grants or patents received, pending or royalties. No writing assistance was done in the production of this manuscript. And the indicated institute is totally no profit, so, this manuscript has the intention of collaborating with the spread of knowledge.

\section{REFERENCES}

[1] Kirsty Greenow, Alan R. Clarke - Controlling the stem cell compartment and regeneration in vivo: The role of pluripotency pathways - Physiol Rev 92: 75-99, 2012 -doi:10.1152/physrev.00040.2010 - C2012 - Table 1.

[2] Laura E. McNamara, Rebecca J. McMurray ET. al. Nanotopographical Control of Stem Cell Differentiation $\mathrm{C} 2010$

[3] Jeremy W. Dale, Malcolm von Schantz, Nicholas Plant From Genes to Genomes: Concepts and Applications of DNA Technology - C2011

[4] Ivan Damjanov, Barbara B. Knowles, Davor Solter - The Human Teratomas: Experimental and Clinical Biology C1983

[5] Charles Babbage et.al. - On the Principles and Development of the Calculator and Other Seminal Writings - C2013

[6] Jun Kawai and Yoshihide Hayashizaki - DNA Book C2003 - DOI: 10.1101/gr.914203

[7] Daniel M Cohen and Christopher S Chen. - Mechanical control of stem cell differentiation - C2008

[8] Matthew L. Jones - Reckoning with Matter: Calculating Machines, Innovation, and Thinking about Thinking from Pascal to Babbage - C2016

[9] Van Berkum, ET. al. - Hi-C: A Method to Study the Three-dimensional Architecture of Genomes. Jove Journal C2010

[10] Jennifer A. Doudna, Samuel H. Sternberg - A Crack in Creation: Gene Editing and the Unthinkable Power to Control Evolution - C2016

[11] Steve Krug - Don't Make Me Think: A Common-Sense 
Approach to Web Usability, 2nd Ed. - 2005

[12] Yun Zhou, Xing Liu, Eric M. Engstrom ET. al. - Control of plant stem cell function by conserved interacting transcriptional regulators - doi:10.1038/nature13853 C2015

[13] Peter N. Kugler, Michael T. Turvey - Information, Natural Law, and the Self-Assembly of Rhythmic Movement C2015

[14] Skylar Tibbits - Self-Assembly Lab: Experiments in Programming Matter - C2016

[15] A Redondo, Paviou, Loizidou - Elements of the niche for adult stem cell expansion - C2017 DOI: $10.1177 / 2041731417725464$

[16] https://www.jove.com/video/1869 - Last access $(07 / 08 / 2017)$

[17] William A. Dembski - Intelligent Design: The Bridge
Between Science \& Theology - C2002

[18] Richard Dawkins - The Greatest Show on Earth: The Evidence for Evolution - C2010

[19] Marc T. J. Johnson and Jason Munshi-South - Evolution of life in urban environments - C2017 - Science - DOI: $10.1126 /$ science.aam8327

[20] Jeremy M Berg, John L Tymoczko, and Lubert Stryer Biochemistry, 5th edition - Chapter 5. - DNA, RNA, and the Flow of Genetic Information - C2002

[21] Harvey J. Graff - Undisciplining Knowledge: Interdisciplinarity in the Twentieth Century - C2015

[22] Bing-Hao Luo, Timothy A Springer, ET. al. - Integrin Structures and Conformational Signalling - C2006.

[23] Donghwi Ko, Ykä Helariutta et. al. Shoot-Root Communication in Flowering Plants - DOI: 10.1016/j.cub.2017.06.054 